\title{
University of Winchester, UK
}

\author{
Andrew Melrose
}

Viva la vida: viva la viva voce

(live the life: live the living voice)

\begin{abstract}
:
Creative writing is comparatively young as a research discipline in universities, with dedicated doctoral programmes in writing only emerging over the past decade or two. As a consequence, there is still considerable uncertainty about the quality of examination in the discipline. This paper is about the viva voce in the Creative Writing $\mathrm{PhD}$ examination process. It addresses the procedures and practice and is accompanied by a rationale which argues the merits of the viva vocel
\end{abstract}

\section{Biographical note:}

Andrew Melrose, DPhil, is Professor of Children's Writing at the University of Winchester, UK. He has over 150 film, fiction, non-fiction, research, songs, poems and other writing credits, including The story keepers film series, a 'textual intervention' on the New Testament, broadcast worldwide, and 33 scholarly or creative books. He is also the editor of the UK-based, international journal Writing4Children and an inaugural member of the international advisory boards of TEXT: journal of writing and writing courses and Axon: creative explorations. In addition to his creative writing, he has written a number of books, articles and book chapters on various aspects of critical and creative writing and on the cult and culture of the child, children and childhood. Here comes the bogeyman: exploring contemporary issues in writing for children and Monsters under the bed: critically investigating early years writing were published by Routledge in 2012 .

Keywords:

Viva voce - Doctorate - Creativity - Examination - Research - Knowledge 
When we wrote the article, 'Understanding the value and the impact of the "shock": examining the creative writing doctorate' (nd), which had been aired as a paper at the Postgraduate Supervision Conference in Stellenbosch, South Africa, Jen Webb and I were aware of how little is known about the creative writing doctorate beyond the small community of creative writing scholars but also the huge similarities in the way the creative writing doctorate was examined in the UK and Australasia. The single exception to the similarities, however, lies in the use of the viva voce as a part of the examination process. It is compulsory in the UK and hardly ever used in Australasia. In discussions we held about this difference we didn't really come to any real conclusions; it was just a case of comparing like for like. What became obvious, though, was that a proper dialogue needed to take place. Being that the "Examination [of a $\mathrm{PhD}$ ] is a process conducted largely in private - it is "shrouded in mystery", to quote a participant in a study of examination' (Webb, Brien \& Burr 2012) - and typically involves examiners who have little if any training in the process' (Webb \& Melrose: under consideration), I decided to try and contextualise the viva voce in the creative writing examination process, as I saw it - not to deliver an empirical benchmark but to open up discussion on the considerable variation of ideas that inevitably exist, because as Burnham has revealed (in a truism that still continues ${ }^{1}$ ):

THE VIVA IS one of the best kept secrets in British Higher education. To all but the initiated what occurs in the lengthy judgely hurdle from which nervous postgraduates emerge either victorious or distraught is a mystery (1994: 30).

Therefore, this is a personal reflection of the best kept secret as I see it, so I guess the easiest way into this paper is to say, firstly, what the viva is, or does, or is expected to achieve.

The viva voce (literally 'living voice') is essentially a conversation between the $\mathrm{PhD}$ candidate and the examiners, which takes place after the candidate has submitted a thesis and the examiners have had a chance to read and examine it. In most British universities these days, the viva is a meeting between the candidate and an examination panel which includes the External Expert Examiner, an Internal Examiner with subject knowledge but who has not been in a supervisory relationship with the candidate, and a Chair, whose role is to ensure the institution's regulations are met and the discussion is fair. There may be other local regulations (which are actually fairly standard but not universal) such as, if the candidate is connected in any formal way with the University beyond being a PhD student (e.g. he or she carries out part time teaching) then there may be a requirement for a second External Examiner to be appointed. Also the issue of experience is considered, for example if the candidate and supervisory team identify a subject expert who has not yet had two successful completions of their own, they may still be invited, but with a second external examiner who does meet the completion rule. In addition, in some cases the candidate's supervisor may attend if the candidate and supervisor agree, but he or she is not allowed to speak, and is normally placed out of the candidate's eye-line. Therefore the room can be quite well populated and there can be a number of witnesses to the discussion and there is no reason why all the parties concerned will not know all of this in advance. And while I say 'the room' it need not even be that - 
since I have been in a successful three-way, video link viva where I was in England, the internal examiner was in Wales and the candidate in the USA.

But in taking care of the logistics, part of the 'mystery' for the candidate is the step into the unknown. Having researched and written their thesis they then have to face examination; and yet, I would contend, the viva actually provides a fantastic opportunity. During the meeting, the candidate is allowed to 'defend' his or her thesis in the face of questions, concerns and issues which the examiners and subject expert have garnered from the thesis that need clarifying before a final, pass, fail or other ${ }^{2}$ decision can be made. As Park says:

[it is] an opportunity for the student to 'defend' the thesis; locate his/her research in the broader context; display detailed knowledge of the thesis and authenticate the work while the examiner is expected to ask questions about the originality of the thesis, and about the contribution the thesis makes to knowledge. The student should also be able to defend the methodology and conclusions of the thesis, and display awareness of the limitations of the thesis, in the viva. For the viva to be regarded as successful, the student should satisfy the examiners that $\mathrm{s} /$ he is worthy of the research degree, which will always be ultimately a matter of academic judgement by the examiners $\left(2003^{3}\right)$.

This makes everything sound very simple indeed and it is. The candidate writes the thesis, the examiners examine it and then both parties meet to discuss and clarify some of the issues raised. What could be simpler? Especially since the panel can eventually go on to become what has been described to me as 'critical friends', as they also edit and ensure that even the slightest factual, grammatical and spelling errors are highlighted and that the final thesis is as good as it can possibly be. Indeed it is very rare for any thesis to be accepted without 'minor corrections'.

Yet, while I have read a great deal of research such as Park's on the viva, and it is quite clear and precise, it is mostly about procedure, about expectations and about calling for academic judgement on a contribution to knowledge without actually providing an intellectual rationale for the viva itself. After researching 'good practice' when I was writing a DCA (Writing) validation document, I wrote this set of criteria for my own institution: a creative writing candidate is expected to demonstrate:

- the creation and interpretation of new knowledge, as embodied in one of: creative art work; a combination of artwork and reflection; or documentation of artwork and reflection. This will be channelled through original researchcreation, in other words advanced, informed, sophisticated creative practice, of a quality to satisfy review by peers, extend the forefront of the discipline, and merit publication, live performance, or other professional dissemination in a framework that defines it as artistic innovation and an original contribution to the field of creative practice;

- a systematic acquisition and understanding of a substantial body of practical knowledge which is at the forefront of an academic discipline or area of professional practice and which is evidenced in the creative work;

- the general ability to conceptualise, design and implement a project for the generation of highly sophisticated creative innovation at the forefront of the 
discipline, and to adjust the project design in the light of unforeseen problems; and,

- a detailed understanding of applicable techniques for creative research and advanced practice-based creative enquiry in an academic context.

All of this will be confirmed after the viva has taken place, and it really tells us nothing, but just alludes to expectations. Of course, I realise the reason for this doubt is that such rationales are subject specific. $\mathrm{PhD}$ research itself seems a perfectly obvious idea; it is a quest for a contribution to knowledge and the thesis is as much about research methodology as potential outcomes. Of course there are differences, the vertical research of a mathematician, for example, where the new contribution to knowledge advances a previous computation (which in itself will, at some time, be overtaken in the future) is not the same as the horizontal research of the artist or writer who is both engaged in research practice, in an understanding that all art comprises an element of research. As well as creating a piece of art the researcher has to develop and experience an understanding of appropriate research methodologies, alongside aesthetic, theoretical, ethical and practical issues relevant to critical and creative research in the arts, and in the philosophical and theoretical approaches that underpin them, so that they are able to contribute to advancing knowledge through practice in their chosen artistic field. In so doing, they will also be developing a critical understanding of the experimental and fragmentary nature of early creative practice, with a commitment to encouraging the artistic creation. This in turn sophisticates a systematic practical, aesthetic and theoretical knowledge, with a critical awareness of methodology and techniques used for creating artistic work. The research underpins the creative process at the same time as the creative process makes demands on expanding critical and theoretical knowledge. What the viva will be looking for is the creation of new and creative approaches that extend or redefine existing knowledge and/or professional practice.

Nevertheless, the role of the examiner(s) or examination panel in the creative viva can be misleading, because in my experience the viva is not a one-sided question and answer process but a discussion, and indeed the candidate is entitled to question the examiners' thoughts and questions. While the examiners make the final decision, the object of the viva is to reach an understanding. But still, simple questions surface. In terms of creative writing, how, for example, does an examiner decide on the merits of the creative piece at the same time as juggling with ideas on methodology, aesthetic judgement and theoretical judgement? The fact that the creative $\mathrm{PhD}$ is composed of two components, the critical and the creative, the research practice and the art practice, is itself problematic. Perhaps it is time to take a step back to think about what the viva process contributes to this.

Leafing through my notebook while gathering research for this article, I came across a random, monostich-like line I had written, which said, 'knowledge doesn't close 
discourse but opens it up; it is a dialogue'. And this helps me to begin qualifying a narrative for a creative writing viva process. In the greatest hits archives of some of the most famous writings by Jacques Derrida, there is a slogan that announces, 'There is nothing outside the text' (1967: 157-64) and for those of us immersed and engrossed in academic textuality, as $\mathrm{PhD}$ supervisors and examiners, it is a convenient bubble in which we can co-exist with the PhD candidates. 'Reality is linguistic,' we could say, 'if it is not on the page it is not in the PhD'. Oh that it were so. But it is not so! There is also real life to deal with: 'a writer is rarely "only" a writer' (Lahire \& Wells 2010: 443-65). Artists do not live in a bubble but amidst the babble that is life. Milan Kundera says, 'Torn away from the history of their various arts, there is not much left to works of art ... For the history of art is perishable. The babble of art is eternal' (2007: 167-8). In the same way, I would contend, the babble of the $\mathrm{PhD}$ is part of the eternal babble in the ongoing project as a unique contribution to knowledge. Indeed, it might also be said that the $\mathrm{PhD}$ itself, the contribution of new knowledge, is like a secret; it doesn't actually exist until we tell others about it so that the ensuing babble can join the ever-expanding critical, creative and theoretical knowledge. In this respect, the creative $\mathrm{PhD}$ is critically creative and creatively critical.

And so, while the external 'examiner is [...] the ideal reader of the text - [and he/she] completes the thesis' (Webb, Brien \& Burr 2012: 6) it might also be suggested that the thesis is still a secret until that first conversation, the 'living voice', has taken place. So let's consider this. As academics in the creative writing field, we also write and we are also already in dialogue with everyone else who writes or has written. The bequest of the written word, the poem, the libretto, the play script, the novel is to be found in the rituals of writing, of which we too are a part. Thus, while the critical and creative dialogue is already ongoing for the writer who wrote the thesis and for the examiner reading it, to my mind the viva is the natural first point of discussion between two people who are already involved in the wider discourse, and the reason for this is very simple. Ultimately, the academic and writer is only confirmed as such by the examiner. The examiner is the person who can declare whether the $\mathrm{PhD}$ candidate is an academic artist or not by legitimising the piece of art the writer created. This is a huge responsibility for any examiner in any discipline but especially one where the examiner's credentials are confronted by subjective issues and ideas that are difficult to define, as well as a theoretical and methodological underpinning As Webb and I have also written:

in the examination of a creative arts doctorate is an element that is, arguably, present across the humanities, arts and social sciences, but has more impact in the creative sector. This is the problem of examination predicated on subjective rather than purely 'scientific', or objective, criteria. In creative doctorates, judgment is necessarily clouded by taste and preference. An examiner who does not read science fiction will find it difficult to provide quality evaluation of a science fiction based thesis, no matter how experienced he or she might be in creative writing, or how skilled in the research domain (nd).

Thus, such a person would not normally be considered as a potential candidate. ${ }^{4}$ Adding to which: 
A further complexity arises in the process of examining creative arts doctorates because of the bifurcated nature of the dissertation; an examiner needs expertise and experience in the art form in which the work is presented, and also in the theoretical and methodological frameworks that provide the scholarly component ... Clearly, an examiner... would need a high level of skill and experience in the field, and there are concerns expressed across the artist-academic community about how to find examiners who do possess the technical, aesthetic and theoretical knowledge (nd).

Thus, it seems to me, a dialogue in the shape of a viva is a perfect way for the two artists to meet to discuss ideas, intention and artistic merit which feed both the 'technical, aesthetic and theoretical knowledge'. Which returns us to the idea that while they are both inevitably 'in dialogue with everyone else who writes or has written' they will also have different ideas on what and how they write and think. But surely this is always a dialogue? For example, I recently had a disagreement with a writer I greatly admire. I wrote:

The well-respected art critic John Berger has said, 'the majority of Picasso's important late works are variations on themes borrowed from other painters ... no more than exercises in painting' (Berger 1972: 183). Is this really the case? ... I am not an art historian ... but Berger's analysis worries me. Because is Picasso's painting not a reinterpretation, a variation on a theme rather than mimicry: as Picasso himself said, 'I am a Spaniard, just like a torero takes his bull through all kinds of passes, I like to take my pictures through all kinds of variations' (ctd Time 1957: 84) (Melrose 2010).

And this got me thinking, wouldn't it have been great to have this as a conversation with John Berger? I might have used for support Terry Eagleton who was to reveal so succinctly:

parody of a sort is not wholly alien to the culture of postmodernism, though it is not one of which it could be said to be particularly conscious. What is parodied by postmodernist culture, with its dissolution of art into the prevailing forms of commodity production, is nothing less than the revolutionary art of the twentiethcentury avant garde. It is as though postmodernism is among other things a sick joke at the expense of such revolutionary avant-gardism, one of whose major impulses, as Peter Bürger has convincingly argued in his Theory of the avant-garde, was to dismantle the institutional autonomy of art, erase the frontiers between culture and political society and return aesthetic production to its humble, unprivileged place within social practices as a whole (Eagleton 1985: 60).

I could go on to suggest Picasso's late work was an attempt to try and understand what art is, as a 'return [of] aesthetic production to its humble, unprivileged place within social practices as a whole'. This implies that Picasso's late pictures, in the style of others, not only reveal Picasso the artist, but also Picasso making connections and a critically creative and creatively critical engagement with a rich artistic past of which he can be entitled to be called part. It is an ongoing discussion, of which Picasso might have had much to add had he been given the chance - in the same way that a viva offers that chance. 
Looking at the bookshelf above the desk I am writing at now, I see a copy of Eliot's 1922 masterpiece The waste land where he acknowledges Ezra Pound in the dedication, as 'il miglior fabbro' - loosely translated as 'the better maker'. It might be said that Eliot's masterpiece came into being partly through Pound's legitimising dialogue. In some sense he was the external examiner of Eliot's work. Indeed, as Webb advised me, Carole Seymour-Jones also makes a strong case for Vivienne Eliot's influence on her husband's development as a poet, particularly for the production of The Waste Land (see, Seymour-Jones 2001) and the role of the supervisor is not too far away from this description of Vivienne's influence. As such, we have an ongoing dialogue in which the examiner finally comes to legitimise and declare as a credible creatively critical and critically creative submissions which the writer and supervisor let go for examination.

Here I am reminded of Kundera's idea that, '[writing] is the art that created the fascinating imaginative realm where no one owns the truth and everyone has the right to be understood' (1988: 159); and to take him a little further down this road, where, 'Every novel says to the reader: Things are not as simple as you think' (Kundera 1988: 18). For the reader who has had the benefit of research into critical thought, Kundera's words could be considered playful as we lean on our critical heritage and theoretical and methodological experience to go on to deconstruct and textually analyse the texts we read. This is an understood role of a critic. But while Roland Barthes may have famously advised us that the corollary of the death of the author is the birth of the reader, and in that making sense itself is the domain of the reader, in the $\mathrm{PhD}$ viva process the examiner is able, nay expected, to bring to the viva an understanding of that which he or she, comprehends is being presented in relation to the wider discourse and theoretical and methodological foundation. The rhetorical slippage, the intentionality and unintentionality, what the writer meant to craft into the piece and that which he or she unwittingly included as a result of culture, sexual, gender and social matters that come as part of being, are all open to discussion. In dismantling the sources of textual influence the examiner can raise questions about ideas and influences which a writer cannot always read in their own work and I think this has to be a good thing in expanding and disseminating ideas in new knowledge which is what a $\mathrm{PhD}$ amounts to. Who among us can really 'know' everything we write? As Kundera also says, 'novels are always a little more intelligent than their authors' (1985) and it seems to me that the viva helps to tease the knowledge out of the creative text. 'I write to find out what I know,' has been attributed to so many writers. (I have seen Don DeLillo, Flanner O'Connor, Stephen King, Mark Twain and Richard Nordquist credited with variations).

We don't all have an Ezra Pound or a Vivienne Eliot to read our every word but if we were to consider this in the context of a PhD process, as a dialogue in itself, it might be easier to see how the viva should function. Because it might also be said that the $\mathrm{PhD}$ itself functions in a similar way to the social world; it is made up of three realms 
called, 'structure', 'culture' and 'agency', and this diagram may help to contextualize that:

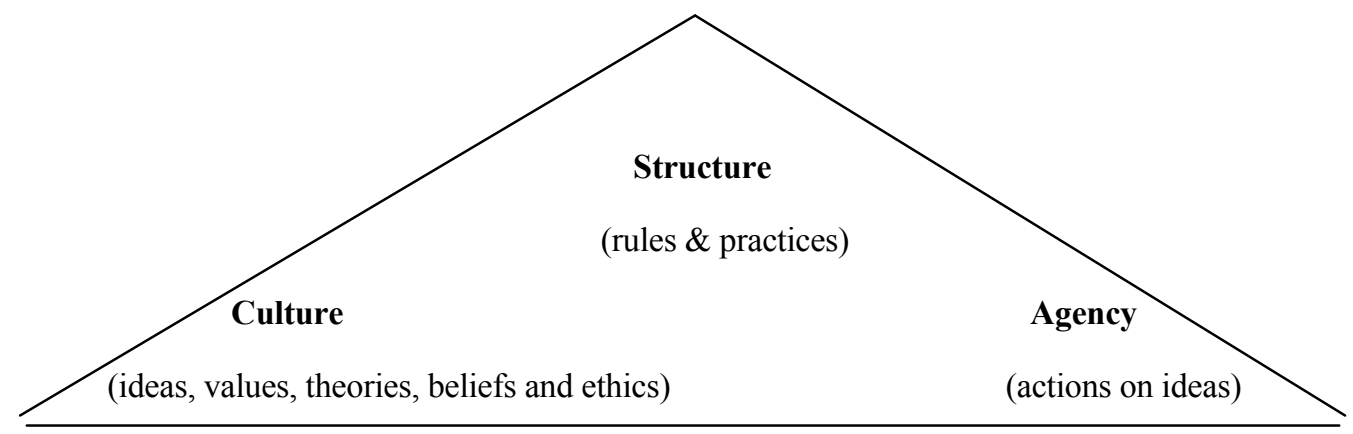

The 'structure' is the institutional requirement, the supervisor, university regulations, support systems and registration; 'culture' is the research and endeavour; and 'agency' is the thesis, the product, the creative artefact. While as critics we may celebrate the freedom poststructuralism allows us, the liberating, decentred universe of ideas as free play, as Derrida might have said, what we are actually doing is examining a creatively critical and critically creative endeavour which has to conform to certain structural considerations. We are not praising it or critiquing it as free critics but interrogating it with a purpose. In this respect, Derrida advised that a reading (such as that which we undertake in examining)

must always aim at certain relationships, unprecedented, unperceived by the writer, between what he commands and what he does not command of the patterns of language that he uses ... to make the not-seen accessible to sight (1967: 158-63).

Taking this a little further, in a non-viva situation we have the conventional dialogue between the writer and the examiners, whereupon the examiners make a decision based on his or her critical engagement, viz:

\section{Writer/Thesis}

Examiners

But I am persuaded here of a three act strategy. Instead of a dialogue to the power of two, A to B and B to A (as we have above in a normal researcher/examiner relationship) we have a dialogue to the power of six:

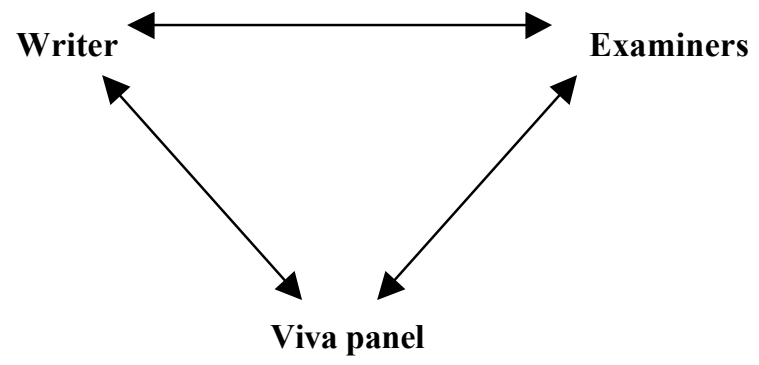


I have always felt that this opportunity to meet at the viva point for discussion, rather than the detached examination from a distant/distanced examiner, allows discussion on the obvious issues of creative practice, critical underpinning, research and methodology. Thus, the examiner takes Derrida's idea of making, 'the not-seen accessible to sight,' asking questions and raising issues about those unseen aporia and ellipses so that the author can defend the creatively critical and critically creative decisions, the artistic product and the critical underpinning and rationale reveal (or not). Indeed, since we can already accept that reading and interpretation are not just about trying to reproduce what the writer expresses, the viva also allows the writer to question the examiner's reading, and indeed surely both will be trying to find common ground - they are after all, as I have already said, both inevitably in dialogue with everyone else who writes or has written and they will also have different ideas on what and how they write. And indeed their own social, cultural, gender, sexual orientation and influences will surely impact on this discussion too. It is much more than just appointing an examiner who understands the genre but engaging an examiner who will engage with the writer, the text and the creative process in a dialogue in order that they may both find common ground (or not). It is almost Foucauldian in aspect, he writes, and 'What strikes me is the fact that, in our society, art has become something related only to objects and not to individuals or to life.' (Foucault 1997: 2611), the artistic PhD thesis is not just about the object but also about the individual and their critical understanding of what they have produced. And to some extent, this returns us to the Berger/Picasso ideas I referred to earlier. In a moment of reverie I can imagine the dialogue between the two of them as the critic and the artist wrestle with meaning.

Artistic meaning is normally a problem for the philosopher and critic to address, or in the case of a $\mathrm{PhD}$ the examiner who takes on this role, because they can only do so after the fact of the artistic production. For the artist, however, the problem of artistic meaning comes earlier since the artistic journey is often embarked on in hope; hope that the end result will result in critical approval. As Fredric Jameson says, 'it is a reinvention of the historical situation alone that allows us to grasp the text as a vibrant historical act, and not as a document in the archives' (2009: 248). Rarely are we given the opportunity to discuss the novel with the novelist, the painting with the painter and so on, the viva offers this rare opportunity. And actually, from this thought, I am drawn to ideas and reflections that appear in the journal, Axon: creative explorations in which the editors, Paul Hetherington and Jen Webb, have a series of dialogues with poets where practice, creativity, poetics and so on are questioned and addressed. See, for example, an extract from Paul talking to the poet and novelist, Judy Johnson;

Judy: Though I didn't plan for my poems to get longer and longer, when I look at my history as a poet it seems like a logical evolution - to begin with small imagistic poems, then to develop an interest in narrative, then to write more expansive narrative poems, and then a verse novel, and then the novel in prose. But what's interesting about that is the novel still feels as if it's not quite my voice ...

Paul: The prose novel? 
Judy: The prose novel. I think it is a different space. I think the verse novel space and the novel spaces are much more different than I thought it would be.

Paul: What is that difference do you think?

Judy: I think it's to do with the size and the looser structure of the novel. And it's to do with the lyrical density in the narrative poem. But it's also to do with the compactness of thought in poetry. The gaps in meaning that are left for the reader to fill in (Hetherington 2013).

The writer, Judy, is being given the opportunity to 'defend' her work and locate her research in the broader context of writing, where she displays detailed knowledge of her thesis and authenticates her work while her examiner, Paul, is asking questions (prompting) about the originality of the thesis, and about the contribution to artistic endeavour - or so it seems to me. In their first encounter they were poles apart and mediated by the creative production (the body of work, the poems, novels etc.),

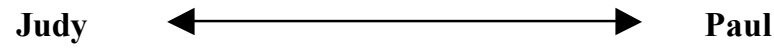

But the conversation has them meeting, thus, after the initial encounter:

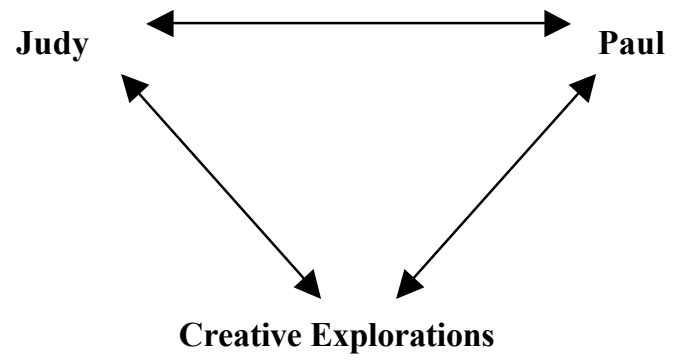

Isn't this an ideal situation, an ideal relationship between writer and critic? To this end, the viva voce may be the one and only chance a new writer and researcher (as $\mathrm{PhD}$ candidates tend to be) has to meet their first critic. Personally I feel this is not just a good thing but something which adds to the fabric of knowledge itself. It has a sound artistic, critical, theoretical, methodological and pedagogic reasoning. Throughout this paper I have tried to weave such threads into the creative thought, in a way that might be obvious to the academic, artistic community, so I close as I opened: knowledge doesn't close discourse but opens it up; it is a dialogue, viva la vida: viva la viva voce.

\section{Endnotes}

1. I have never had any tuition on the viva process although I am aware of the research available.

2. Other decisions can be a suggestion to re-write, take more time and re-submit.

3. I have paraphrased this for clarity, since Park presents it as a bullet pointed list.

4. External examiners are usually appointed following discussion between the supervisors and the candidate in order to identify experts in the field. 


\section{Works cited}

Axon: creative explorations, at http://www.axonjournal.com.au

Burnham, P 1994 'Surviving the viva: unraveling the mystery of the PhD oral' Journal of graduate education 1, 30-4

Derrida, Jacques 1967 Of grammatology Baltimore: John Hopkins UP

Eagleton, Terry 1985 'Capitalism, modernism and postmodernism' New left review 152 (July-August), $60-73$

Foucault, Michele 1997 Ethics: essential works of Foucault 1954-1984 1, ed Paul Rabinow, London: Penguin

Hetherington, Paul 2013 'Lifeline and reclamation', Axon: creative explorations 4, at http://www.axonjournal.com.au/issue-4/lifeline-and-reclamation (accessed 5 July 2013)

Jameson, Frederic 2009 'Afterword', in Stephen Ross (ed) Modernism and theory: a critical debate, London: Routledge, 2247-52

Kundera, Milan 1985 'Jerusalem address: Europe and the novel', in Pro Europa, at http://www.proeuropa.eu/index.php?option $=$ com_content\&view $=$ article $\&$ id $=354$ :kundera-europe-and-thenovel\&catid=27:spirit\&Itemid=61 (accessed 12 July 2008)

Kundera, Milan 2007 The curtain: an essay in seven parts, trans L Asher, London: Faber and Faber

Lahire, Bernard \& Gwendolyn Wells 2010 'The double life of writers' New literary history 41: 2 (Spring), 443-65

Melrose, Andrew 2010 'Jesus, Judas, Jimi and John: culture, communication, media and art in delightful chaos' TEXT: journal of writing and writing courses 14: 1, at http://www.textjournal.com.au/april10/melrose.htm (accessed 5 July 2013)

Park, C 2003 'Levelling the playing field: towards best practice in the doctoral viva' Higher education review 36: 1, 47-67

Seymour-Jones, Carole 2001 Painted shadow: a life of Vivienne Eliot, New York: Random House

Webb, Jen, Donna Lee Brien \& Sandra Burr 2012 Examination of doctoral degrees in creative arts: process, practice and standards, Canberra: Australian Government Office for Learning and Teaching

Webb, Jen \& Andrew Melrose (under consideration) 'Understanding the value and the impact of the 'shock': examining the creative writing doctorate' New writing: the international journal for the practice and theory of creative writing 